Brit. J. prev. soc. Med. (1975), 29, 82-90

\title{
Mortality from arteriosclerotic disease and consumption of hydrogenated oils and fats
}

\author{
LEO H. THOMAS \\ Chemistry Department, Glamorgan Polytechnic, Treforest, Glamorgan
}

\begin{abstract}
Thomas, L. H. (1975). British Journal of Preventive and Social Medicine, 29, 82-90. Mortality from arteriosclerotic disease and the consumption of hydrogenated oils and fats. Consumptions of chemically modified hydrogenated fat are estimated for the United Kingdom standard regions, conurbations, and urban/rural aggregates as well as for the social classes. Consumptions are shown to correlate satisfactorily with mortality from arteriosclerotic disease and account reasonably well for certain peculiarities in the ratio of female to male death rates and for secular changes in mortality patterns.
\end{abstract}

A possible causal relationship between arteriosclerotic disease and quantity and/or quality of dietary fat has long been postulated, and many aspects of the problem have been the subject of much debate and a somewhat lesser amount of critical experimentation. It appears to the author that one particular aspect has been given less attention, namely the possibility that chemically modified oils and fats may, as such, have adverse effects. Quite apart from the presence of a variety of additives, the main modifications arise through the process of hydrogenation whereby a liquid oil is converted into a less unsaturated solid or semisolid fat for use in the manufacture of margarine, shortenings, and cooking fats/oils. Hydrogenated fat (HF) contains glycerides that are structurally different from their isomers present in natural oils and fats in amounts up to as high as $40 \%$. Since about 1960, cheap marine-animal and fish oils have been increasingly used for the purpose, and these give rise to the presence of saturated and lightly unsaturated glycerides of fatty acids of chain-length in excess of $\mathrm{C}_{18}$-namely, $\mathrm{C}_{20}$ and $\mathrm{C}_{22}$ acids-which, are virtually absent in traditional fat sources.

In so far as man has had no cause until recently to adapt to such 'unnatural' material, it seems prudent to question the safety of HF, especially as it is consumed in large quantities.

In the United Kingdom at least, the consumption of $\mathrm{HF}$ varies according to the standard region or urban/rural aggregates, and also social class. The hypothesis that HF as such may be harmful should therefore be capable of examination by compariso ot with corresponding mortalities. In particular, in far as the working man consumes more meads outside the private household than the domiciled housewife, we may expect that the ratio of male to female death rate would be revealing.

\section{TRENDS IN FAT CONSUMPTION IN THE UNITED KINGDOM}

Some statement regarding the general picture of fat consumption in the United Kingdom would appear to be desirable in order to assess more meaningfully the effects of differing HF consumptions. In fact, the national consumption of visible and invisable fats rose slightly after de-rationing in 1954, but since 1960 (all figures in g/person per day, fat content) it has remained sensibly constant at around 음 $62 \mathrm{~g}$ (visible) and $81 \mathrm{~g}$ (invisible). The same is true $>$ of butter $(20 \mathrm{~g})$ and 'lard and compound cooking fat' (16g). Consumption of margarine, however- N and concomitantly $\mathrm{HF}$-has steadily declined from about $19 \mathrm{~g}$ before de-rationing to $16 \mathrm{~g}$ during the $\stackrel{0}{ }$ five-year period up to 1960 , to $12 \mathrm{~g}$ from 1967 tow 1971 inclusive.

Regional differences, including London, in totake fat consumption were remarkably small and no region differed from the United Kingdom average? (143g, since 1960$)$ by more than $2 \mathrm{~g}$, with the exception of Scotland which showed a figure about $10 \mathrm{~g}$ below average. For total butter-fat (which includes dairy products in addition to butter) Wales, the South 
West, South East and London were above average $(43 \mathrm{~g})$ by about $4 \mathrm{~g}$, the two Midland regions had an average consumption, and the remaining regions $2-4 \mathrm{~g}$ less than average.

Regional differences in HF consumption are considered below, but generally areas having high HF consumption have low butter-fat consumption.

The above figures are taken from the Ministry of Agriculture, Fisheries and Food Household Food Consumption and Expenditure, Annual Reports of the National Food Survey Committee 1955-1971 (NFSC).

\section{METHODOLOGY}

The three sub-sections which follow deal with matters of technical detail and definition, and may be omitted if desired from first reading. The statistical evidence is then presented in such order that correlations based on more controversial premises are deferred to the later pages.

\section{COMPARABILITY OF REgIONS AND \\ Urban/Rural Aggregates}

The standard geographical regions were revised by the Registrar General (RG) in 1965, but except for parts of Lincolnshire that were transferred from the East Midlands to Yorkshire and Humberside, the changes are minor in the context of this paper. The naming of the standard regions in the tables that follow is that of the post-1965 period.

Changes in definition of the Greater London conurbation were of greater magnitude, but because mortalities and HF consumptions differed only slightly in contiguous areas of the South East region, these are not regarded as significant.

The regional basis adopted by the NFSC coincides with that of the RG, except that the NFSC includes East Anglia with the South East region; likewise for Greater London.

The NFSC includes conurbations and towns in Scotland, whereas this paper deals with mortalities in such areas in England and Wales only. Bearing in mind relative populations, however, the difference is not thought to be of significance. Subject to the same limitation, the RG 'rural districts' can be identified with the NFSC 'rural areas' plus 'semi-rural areas'.

\section{Comparability of Social Class}

The RG's social classes are designed along broad lines to reflect a man's occupation, and to convey 'some idea of his income, intelligence and education'. In the 1961 census, social class 1 (professional etc., occupations) accounted for $5 \%$ of the male working population of England and Wales; social class 2 (intermediate occupations) $15 \%$; social class 3 (skilled occupations) $51 \%$; social class 4 (partlyskilled occupations) $20 \%$; and social class 5 (unskilled occupations) $9 \%$.

The classification adopted by the NFSC, however, rests purely on the income of the head of the household, the income being periodically adjusted so as to aim at proportions, group A1 ( $2 \frac{1}{2} \%$ of the population); $\mathrm{A} 2$ ( $\left.7 \frac{1}{2} \%\right) ; \mathrm{B}$ and $\mathrm{C}$ each with $35 \%$; and $D$, the lowest income group, $20 \%$. Group D is sub-divided into D1 (around 9\%)-households with earners; D2-households with no earners; and a third group dependent on old-age pensions.

In spite of the obvious difficulties, the author has equated the following:

$$
\begin{aligned}
\text { Social class } 1 & \equiv \mathrm{A} 1 \\
\text { Social class } 2 & \equiv \mathrm{A} 2 \\
\text { Social class } 3 & \equiv \mathrm{B} \\
\text { Social class } 4 \text { plus } 5 & \equiv \mathrm{C} \text { plus } \mathrm{D} 1
\end{aligned}
$$

In making comparisons between the 1961 and 1951 periods, it must be taken into consideration that many occupation orders included under social class 5 in 1951 were transferred to class 4 in the later period. The above combination of classes 4 and 5 is therefore further justified.

\section{Evaluation of HF Consumption}

All quantities given below are in g/person/per day.

The NFSC lists data for household consumption of butter, margarine, 'lard and compound cooking fat', suet, 'vegetable and salad oils' and 'all other fats'-the last three items accounting for only about $8 \%$ of the total visible fat-as well as such fatcontaining items as cakes, biscuits, etc. The Survey also provides estimates of total consumption of principal foods (that is, including consumption outside the private household) under the heading 'moving into consumption'.

One particular difficulty arises regarding the item 'lard and compound cooking fat', namely, that of ascertaining the proportion of lard as such. The only estimate which seems to be available is that of Brech (1959) who estimated the percentage of lard as 70 for all regions except Yorkshire and Humberside (90) and Scotland (10). Subtraction of these figures from 100 then gives percentage amounts for cooking fat and/or shortenings which can be taken as hydrogenated material. Fortunately, the relative magnitudes involved $(30 \%$ of the United Kingdom average for 'lard and compound cooking fat' is only $2 \cdot 5 \mathrm{~g}$ compared with a total HF figure of $31 \cdot 1 \mathrm{~g}$ ) does 
not result in any serious uncertainty regarding the relative positions of the regions in total HF order.

Quantities of butter bought as such for household consumption are virtually identical with amounts 'moving into consumption'. Similar comparison regarding butter-fat content of other dairy products shows that about $2 \mathrm{~g}$ butter-fat is consumed outside the home, but it can safely be assumed that such a small quantity is consumed through beverages and dairy ice-cream. Quantities of butter-fat consumed via fat-containing items of food such as cakes, biscuits, etc. are therefore negligible; in other words, such items can be taken as HF-containing food.

The amount of fat consumed outside the private household can be estimated by construction of a 'fat-balance' in respect of all oils and fats other than the intrinsic fat content of meat, fish, eggs, cereals, etc. This gives the information that during the period 1962 to 1971 inclusive, $2 \cdot 83 \mathrm{~g}$ on average was so consumed via cakes, biscuits, crisps, etc., and $0 \cdot 73 \mathrm{~g}$ via ice-cream. A further amount $(3 \cdot 36 \mathrm{~g})$, which is assumed to be hydrogenated or suspect for an additional reason to be discussed later, was used essentially for frying purposes in restaurants and canteens.

Details of the calculations involved are not recorded in this paper; the total figure $(6.92 \mathrm{~g})$ is in any case small compared with total household HF consumption, and may be subject to appreciable error without significant effect on subsequent calculations. This will clearly be particularly true for women.

\section{CORrelation of Mortality and HF CONSUMPTION}

Table I tabulates HF consumption in g/person? per day for the period 1962 to 1971, and standardized mortality ratio (SMR) for men and women whoo were aged between 25 and 64 years in 1968 to 1971.들

Column 2 of Table I lists household consumptions $\overline{\bar{\omega}}$. of HF arising from margarine which was purchased $\Phi$ as such, together with appropriate fractions of the NFSC's estimates of 'lard and compound cookings fats'. Column 3 gives estimates of HF consumption. via such fat-containing items as 'cakes and pastries', $\vec{\omega}$ 'buns, scones, and tea-cakes', biscuits, crisps, pies,, chips, ice-cream, etc. Column 4 represents theס previous two columns added together, and is then? an estimate of total $\mathrm{HF}$ consumption in private ${ }_{\mathcal{O}}^{N}$ households. The absolute magnitudes shown are, of $u$ course, subject to error, but the relative positions can be accepted with some confidence. The relative order has furthermore remained unchanged sincethe early 1950 s and this confirms the acceptabilityc of the tabulated rank orders.

Column 5 gives an estimate of the amounts of $\mathrm{HF}_{\overrightarrow{0}}$ consumed outside the home (precise figures for meals consumed outside the home are not available This was obtained from the amount $6 \cdot 92 \mathrm{~g} /$ pers per day by assuming that it was consumed proportion to the fraction of 'economically active' persons in the various regions, etc., in accordance with the 1961 census. Column 6 is the total of $\stackrel{1}{2}$ columns 4 and 5 . Columns 7 and 8 show the rank $\vec{\circ}$ orders for home and total HF consumptions $\exists$ respectively.

TABLE I

UNITED KINGDOM-HYDROGENATED FAT CONSUMPTION 1962-1971, GRAMS PER PERSON PER DAY ISCHAEMIC HEART DISEASE SMR AGES 25 TO 64, 1968-1971

\begin{tabular}{|c|c|c|c|c|c|c|c|c|c|c|c|c|c|c|}
\hline & \multirow[t]{2}{*}{2} & 3 & 4 & \multirow[t]{2}{*}{5} & \multirow{3}{*}{$\begin{array}{c}6 \\
\text { g/day } \\
\text { Total }\end{array}$} & \multirow{2}{*}{\multicolumn{2}{|c|}{$\begin{array}{cc}7 & 8 \\
& \\
\text { Rank } & \text { Order }\end{array}$}} & \multicolumn{5}{|c|}{$\begin{array}{ccccc}9 & 10 & 11 & 12 & 13 \\
\text { Ischaemic } & \text { Heart } & \text { Diseaso, } & \text { Age } & \text { 25-64 } \\
\end{array}$} & \multirow{3}{*}{$\begin{array}{c}14 \\
\text { Sex } \\
\text { Ratio }\end{array}$} & \multirow{3}{*}{$\begin{array}{c}15 \\
\\
\text { Sex } \\
\text { Ratio } \\
\text { Rank } \\
\text { Order }\end{array}$} \\
\hline \multirow[b]{2}{*}{ Region or Type } & & & & & & & & & & & ank C & Drder & & \\
\hline & $\begin{array}{c}\text { Margarine } \\
\text { etc. }\end{array}$ & $\begin{array}{l}\text { Cakes } \\
\text { etc. }\end{array}$ & Home & $\begin{array}{l}\text { Out of } \\
\text { Home }\end{array}$ & & Home & Total & $\mathbf{M}$ & $\mathbf{F}$ & $\mathbf{M}$ & $\mathbf{F}$ & $\mathbf{M} \& \mathbf{F}$ & & \\
\hline 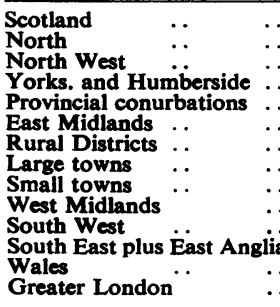 & $\begin{array}{l}15 \cdot 80 \\
15 \cdot 63 \\
16 \cdot 32 \\
14 \cdot 94 \\
14 \cdot 50 \\
14 \cdot 54 \\
14 \cdot 29 \\
13 \cdot 00 \\
13 \cdot 08 \\
12 \cdot 55 \\
11 \cdot 14 \\
11 \cdot 10 \\
10 \cdot 45 \\
9 \cdot 03\end{array}$ & $\begin{array}{l}13 \cdot 08 \\
12 \cdot 43 \\
11 \cdot 58 \\
12 \cdot 84 \\
12 \cdot 23 \\
10 \cdot 85 \\
10 \cdot 69 \\
11 \cdot 83 \\
11 \cdot 62 \\
10 \cdot 00 \\
11 \cdot 34 \\
10 \cdot 53 \\
10 \cdot 45 \\
10 \cdot 25\end{array}$ & $\begin{array}{l}28 \cdot 9 \\
28 \cdot 1 \\
27 \cdot 9 \\
27 \cdot 8 \\
26 \cdot 7 \\
25 \cdot 4 \\
25 \cdot 0 \\
24 \cdot 8 \\
24 \cdot 7 \\
22 \cdot 6 \\
22 \cdot 5 \\
21 \cdot 6 \\
20 \cdot 9 \\
19 \cdot 3\end{array}$ & $\begin{array}{l}6 \cdot 60 \\
6 \cdot 40 \\
7 \cdot 09 \\
6 \cdot 97 \\
7 \cdot 25 \\
6 \cdot 92 \\
6 \cdot 36 \\
6 \cdot 92 \\
6 \cdot 56 \\
7 \cdot 25 \\
6 \cdot 40 \\
7 \cdot 13 \\
6 \cdot 28 \\
7 \cdot 65\end{array}$ & $\begin{array}{l}35 \cdot 5 \\
34 \cdot 5 \\
35 \cdot 0 \\
34 \cdot 8 \\
34 \cdot 0 \\
32 \cdot 3 \\
31 \cdot 3 \\
31 \cdot 7 \\
31 \cdot 3 \\
29 \cdot 8 \\
28 \cdot 9 \\
28 \cdot 8 \\
27 \cdot 2 \\
26 \cdot 9\end{array}$ & $\begin{array}{r}1 \\
2 \\
3 \\
4 \\
5 \\
6 \\
7 \\
8 \\
9 \\
10 \\
11 \\
12 \\
13 \\
14\end{array}$ & $\begin{array}{r}1 \\
4 \\
2 \\
3 \\
5 \\
6 \\
8 \\
7 \\
9 \\
10 \\
11 \\
12 \\
13 \\
14\end{array}$ & $\begin{array}{r}128 \\
113 \\
119 \\
109 \\
114 \\
93 \\
88 \\
106 \\
102 \\
99 \\
96 \\
89 \\
121 \\
93\end{array}$ & $\begin{array}{r}168 \\
136 \\
131 \\
120 \\
124 \\
95 \\
89 \\
108 \\
99 \\
94 \\
85 \\
79 \\
127 \\
82\end{array}$ & $\begin{array}{c}1 \\
5 \\
3 \\
6 \\
4 \\
11 \frac{1}{2} \\
14^{4} \\
7 \\
8 \\
9 \\
10 \\
13 \\
2 \\
11 \frac{1}{2}\end{array}$ & $\begin{array}{r}1 \\
2 \\
3 \\
6 \\
5 \\
9 \\
11 \\
7 \\
8 \\
10 \\
12 \\
14 \\
4 \\
13\end{array}$ & $\begin{array}{c}1 \\
4 \\
2 \frac{1}{2} \\
6 \\
5 \\
10 \\
13 \\
7 \\
8 \\
9 \\
11 \\
14 \\
2 \frac{1}{7} \\
12\end{array}$ & $\begin{array}{r}132 \\
128 \\
112 \\
111 \\
110 \\
102 \\
97 \\
102 \\
97 \\
96 \\
88 \\
87 \\
105 \\
88\end{array}$ & $\begin{array}{c}1 \\
2 \\
3 \\
4 \\
5 \\
7 \frac{1}{2} \\
9 \frac{1}{2} \\
7 \frac{1}{2} \\
9 \frac{1}{2} \\
11 \\
12 \frac{1}{2} \\
14 \\
6 \\
12 \frac{1}{2}\end{array}$ \\
\hline $\begin{array}{l}\text { Wales (South East) } \\
\text { Wales (remainder) }\end{array}$ & - & - & - & - & - & - & - & $\begin{array}{l}127 \\
108\end{array}$ & $\begin{array}{r}143 \\
91\end{array}$ & - & - & - & $\begin{array}{r}113 \\
83\end{array}$ & - \\
\hline All households .. & $12 \cdot 96$ & $11 \cdot 26$ & $24 \cdot 22$ & $6 \cdot 92$ & $31 \cdot 14$ & - & - & 100 & 100 & - & - & - & 100 & - \\
\hline
\end{tabular}


The disparity in 'economically active' men and women in the United Kingdom is such that the $6.92 \mathrm{~g}$ would break down into about $9 \cdot 72 \mathrm{~g}$ per male and about $4 \cdot 45 \mathrm{~g}$ per female. It is important to realize therefore that uncertainty in allocation of this extra $\mathrm{HF}$ is greater for men. In other words, whereas the total HF rank order of column 8 (which differs little from that of column 7) is expected to be close to the 'true', but unknown, order in respect of women, it cannot be expected to perform as well for men.

Columns 9 and 10 show the age standardized mortality ratio averaged over the four years 1968 to 1971 for men and women respectively, at ages 25 to 64 for ischaemic heart diseases as defined by the categories $410-414$ of the 8th Revision of the International Classification of Diseases. Columns 11 and 12 show the rank order of the SMRs, and column 13 combines these ranks for both sexes.

The intensity of the association between HF consumption and mortality rank orders may be assessed through Spearman's rank order correlation coefficient R(s) (Kendall, 1970); these are shown in Table II.

\section{TABLE II}

SPEARMAN RANK ORDER CORRELATION COEFFICIENT (Rs) BETWEEN HYDROGENATED FAT CONSUMPTION AND ISCHAEMIC HEART DISEASE SMR

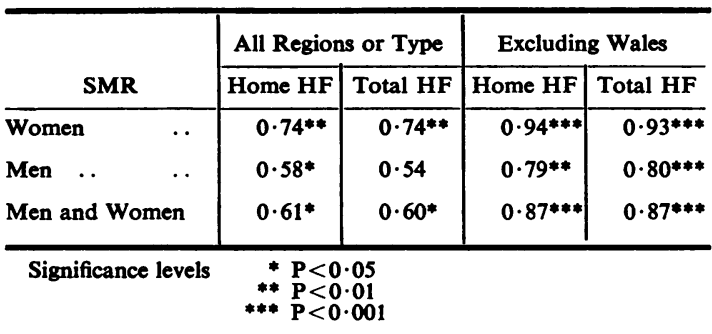

The first two columns show that for all regions or types there is, as expected, only a weak association between HF consumption and mortality from ischaemic heart disease in men, but there is a fairly strong association for women. Table I, however, suggests that the experience of Wales is exceptional, and it is tempting to consider rank order excluding Wales.

The exclusion of an observation post hoc is, of course, a dangerous statistical manoeuvre. Such exclusion, however, materially increases the $R(s)$ as can be seen from the last two columns of Table II.

One source of fat which has not hitherto been included, and over which there is considerable uncertainty, is fat consumed outside the home in fish and chip shops. The uncertainty arises from two points- (a) such fat appears to be highly variable in composition (private information, National Federation of Fish Friers) depending on availability and relative prices, (b) although certain preferences may persist with time, for example, the West Riding of Yorkshire is traditionally a dripping-using area, it is not known how the different types of cooking media are spread between differing regions (ibid).

It seems likely, however, that more expensive oil will contain less hydrogenated material, whereas the cheaper oils will contain hydrogenated fish-oils. For reasons already given, the cheaper oils may be particularly suspect, and poorer regions or classes may therefore be particularly at risk. A disturbing development over the last few years is the incorporation of rapeseed oil in cheaper oils, and to a lesser extent in margarine. Like the hydrogenated fish-oils, rapeseed oil contains large quantities of monoenoic $\mathbf{C}_{22}$ acid (erucic acid) and it has been shown experimentally by a number of workers to be associated with cardiac fat accumulation and damage to the heart (and kidney) in a variety of animals.

On the basis of regional statistics regarding the number of fish and chip shops and turnover (Department of Trade and Industry, 1972 Catering Trades 1969: Statistical Inquiry), we may estimate consumptions from the total figure of 85000 tons per annum of oils and fats used by such establishments in Great Britain in 1969. This figure was supplied privately through the National Association of Fish Friers who also kindly gave the information that total consumption has remained essentially unchanged during the past twenty years or so. Thus on the reasonable premise that the amounts of fat consumed were proportional to turnover, we arrive (after deducting fat contents of the NFSC's figures for chips bought for home consumption) at a figure of $3.00 \pm 0.08 \mathrm{~g}$ for the East and West Midlands and the South East, and slightly higher at $3.40 \pm$ $0.08 \mathrm{~g}$ for the North, South West, and London. For the other regions, however, the figures are much higher at around $5 \cdot 7 \mathrm{~g}$ (Wales $5 \cdot 43 \mathrm{~g}$; Scotland $6 \cdot 60 \mathrm{~g}$ ), thereby further increasing in a general way the disparity between the 'good' and 'bad' areas.

These figures are broadly in keeping with regional preferences as reflected in the NFSC's statistics for chips bought to consume at home. The addition of such quantities does not alter the relative order previously calculated, except that figures for two regions, Yorkshire and Humberside, and the North West, are reversed. However, in view of the preference of the former region for suet, such reversal is probably not justified. 
The Welsh region, however, now attains sixth position in the 10 ranks compounded from the nine standard regions plus Greater London (no data are available for provincial conurbations and urban/rural aggregates), which is somewhat more in keeping with its mortality. More reliable information regarding quantity and quality of frying oils used in the Principality would clearly be of interest. There is no doubt, however, that mortality in Wales-especially in the South East-is exceptional.

Table I shows that the mortality experience in rural districts is somewhat anomalous, and has SMRs about 10 units lower than expected from estimated HF consumptions. In rural areas, however, the number of meals consumed outside the home (other than through packed lunches) can be expected to be lower than in other regions or types, and fish and chip shops are likely to be less accessible. The discrepancy is therefore in the expected direction.

The use of SMR as the sole measure of mortality fails to reveal one important feature, namely, that a bad area shows particularly high mortality at early age, whereas a good area shows low relative mortality in early life. For example, for ischaemic heart disease (IHD) during the period 1968 to 1971 the age-specific mortality ratios (men) for the four agegroups 25 to 44,45 to 54,55 to 64 , and 65 to 74 were $128,116,110$, and 108 respectively for the North; and 85, 92, 94, and 97 for Greater London. This greater risk at an earlier age in a poor region may well be associated with high consumption of cheaper oils and fats outside the private household.

Mortality from cerebrovascular disease (ICD, 8th Revision, 430-438) during the 1968 to 1971 period is almost precisely parallel to the order in respect of IHD; the highest mortality again appearing for Scotland, the North and North West, and Wales, and lowest for the South and South East, including London. Such a pattern is found also in unrelated disease, and it is as well to re-examine the mortality position through the function (deaths from ICD $410-414$ plus $430-438) \div$ (total deaths, all causes $\frac{\pi}{\Phi}$ other than through accident). The rank order for? this function is in fact very similar to that of columns 11 and 12 of Table I.

\section{Secular Changes in Regional Mortality}

Before de-rationing in 1954 (since which time HF $\frac{\text { के }}{\widehat{C}}$ consumption has fallen) any differences in $\mathrm{HF} \cong$ consumption during the previous 15 years between one region and another were, of course, negligible. $\overrightarrow{0}$ It can therefore be stated that the rate of fall-off in a given region since 1954 is determined simply by $\vec{\sigma}$ the consumption at any later date, including the 1962 to 1971 period. In other words, a region of lows 1962 to 1971 consumption has a high rate of fallingî HF consumption and should be showing some improvement in mortality rates relative to a regionos of high consumption. This is indeed true as shown by the death rates from coronary disease in Table III. In spite of the complication over the change in $\vec{C}_{\bar{C}}$ international classification of the disease in the 8th Revision of 1968 , relative changes in mortality are considered meaningful. Rates are given in deaths $\vec{\varphi}$ per million living.

The experience of Wales is again exceptional axd the region continues to show marked deterioration.

Broadly similar changes occur for women at 65 to 74 , and the relative order is not materially affected even if we take percentage changes. For men, too $\mathbb{D}$ rate increases broadly follow the expected pattern at ages 25 to 44 ; at a more advanced age regional differences in rate increases become less marked and correlate less satisfactorily as may have beent anticipated. For the South East, however, and particularly for London, there remains a marked? improvement in male mortality at all ages relative to other regions.

The great (relative) improvement in Greateri London is particularly noteworthy, and follows aj

TABLE III

DEATH RATES FROM CORONARY DISEASE WOMEN AGED 45-64 AND MEN AGED 25-44

\begin{tabular}{|c|c|c|c|c|c|c|c|c|c|c|c|c|}
\hline \multirow{2}{*}{\multicolumn{4}{|c|}{ Region }} & \multicolumn{2}{|c|}{$\begin{array}{c}\text { Period 1958-61 } \\
\text { ICD 7th Revision } \\
420\end{array}$} & \multicolumn{2}{|c|}{$\begin{array}{c}\text { Period 1968-71 } \\
\text { ICD 8th Revision } \\
410-414\end{array}$} & \multicolumn{2}{|c|}{ Rate Increases } & \multicolumn{2}{|c|}{ Rank Order } & \multirow{2}{*}{$\begin{array}{c}\text { Rank Order } \\
\text { Home Total } \\
\text { H. Fat }\end{array}$} \\
\hline & & & & $\mathbf{F}$ & $\mathbf{M}$ & $\mathbf{F}$ & $\mathbf{M}$ & $\mathbf{F}$ & $\mathbf{M}$ & $\mathbf{F}$ & $\mathbf{M}$ & \\
\hline $\begin{array}{l}\text { Scotland } \\
\text { North } \\
\text { North West } \\
\text { Yorks. and H } \\
\text { East Midland } \\
\text { West Midland } \\
\text { South West } \\
\text { South East pl } \\
\text { Wales } \\
\text { Greater Lond }\end{array}$ & 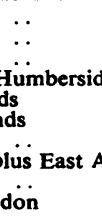 & $\begin{array}{c}\because \\
\therefore \\
\text { ide } \\
\ldots \\
\cdots \\
\text { Anglia } \\
\ldots \\
\ldots\end{array}$ & $\begin{array}{l}\cdots \\
\cdots \\
\cdots \\
\cdots \\
\cdots \\
\cdots \\
\cdots \\
\cdots\end{array}$ & $\begin{array}{r}1445 \\
1215 \\
1110 \\
1064 \\
816 \\
826 \\
902 \\
747 \\
1077 \\
746\end{array}$ & $\begin{array}{l}366 \\
304 \\
332 \\
297 \\
231 \\
264 \\
225 \\
224 \\
358 \\
249\end{array}$ & $\begin{array}{l}1954 \\
1585 \\
1531 \\
1397 \\
1073 \\
1057 \\
1002 \\
913 \\
1455 \\
950\end{array}$ & $\begin{array}{l}451 \\
439 \\
455 \\
405 \\
327 \\
353 \\
287 \\
277 \\
445 \\
290\end{array}$ & $\begin{array}{l}509 \\
370 \\
421 \\
333 \\
257 \\
231 \\
100 \\
166 \\
378 \\
204\end{array}$ & $\begin{array}{r}85 \\
135 \\
123 \\
108 \\
96 \\
89 \\
62 \\
53 \\
87 \\
41\end{array}$ & $\begin{array}{r}1 \\
4 \\
2 \\
5 \\
6 \\
7 \\
10 \\
9 \\
3 \\
8\end{array}$ & $\begin{array}{r}7 \\
1 \\
2 \\
3 \\
4 \\
5 \\
8 \\
9 \\
6 \\
10\end{array}$ & $\begin{array}{r}1 \\
2 \\
3 \\
4 \\
5 \\
6 \\
7 \\
8 \\
9 \\
10\end{array}$ \\
\hline
\end{tabular}


marked drop in margarine consumption from a common figure of about $19 \mathrm{~g}$ during the war years to $8 \cdot 1 \mathrm{~g}$ during 1962 to 1971 , the highest decrease shown for any region. Over this period consumption of butter-fat increased sharply in the London region, with total fat-content of household diet remaining at about national average. This good health record does not appear to lend support to the widely held views that coronary disease is associated with (relatively) highly saturated animal fat and stress conditions. The same point arises later in connexion with social-class mortalities.

\section{Consumption of HF and the Death Rate OF MEN:WOMEN DUE TO \\ ISCHAEMIC HeART Disease}

Comparison of the death rates of men and women over the various regions has the advantage that one sex acts as a 'control' to the other, thereby making some allowance for geographical and social differences. To make such comparisons more meaningful, the author uses a standardized ratio which removes the effects of regional variations in the sex/age structure using the total female:male death rates for England and Wales as standard. The age-groups used for this purpose are 25 to 44,45 to 54 , and 55 to 64 . If $n$ refers to one of these age groups, then we may define the function:

Standardized sex mortality ratio $($ SSMR) $=$

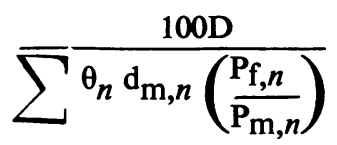

where $\mathbf{D}=$ number of deaths of women aged 25 to 64 for a particular region

$$
\begin{aligned}
& \mathrm{d}_{\mathrm{m}, n}=\begin{array}{l}
\text { number of deaths of men in the } \\
\text { age-group } n
\end{array} \\
& \mathbf{P}_{\mathrm{m}, \boldsymbol{n}}=\text { population of men in age-group } n \\
& \mathbf{P}_{\mathrm{f}, \boldsymbol{n}}=\text { population of women in age-group } \boldsymbol{n}
\end{aligned}
$$

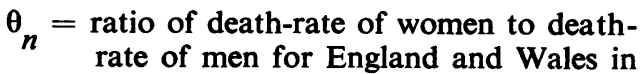

The denominator in the expression for SSMR is the number of deaths of women one would expect in the region if the ratio female : male death-rates for each age-group were the same as for England and Wales.
The SSMRs averaged during the period 1968 to 1971 are printed in column 14 of Table I, and the corresponding rank order in column 15 .

The remarkable fact emerges that the order of decreasing SSMRs follows very closely that of decreasing female SMRS with $R(s)$ for the 14 ranks $=0.96$. Thus a high mortality area has the highest standardized female : male mortality in spite of the greater susceptibility of men at all ages. It should also be noted that Wales is not exceptional in this respect.

It is difficult to see how this mortality peculiarity could arise from differences in, say, climate, socialclass structure, and occupation, or even on genetic grounds. On the other hand, it is precisely what one would expect if $\mathrm{HF}$ were a causative factor. It can, therefore, be expected that the SSMR can be expressed as some function of relative quantities of such fat consumed, that is:

$$
\operatorname{SSMR}=f\{(x+\alpha) /(x+\beta)\}
$$

In this equation, $x$ is the quantity of HF consumed per person in the private household and which varies from region to region (column 4, Table I). $\alpha$ is the extra amount consumed by women outside home and $\beta$ the amount so consumed by men.

Evaluation of $\alpha$ and $\beta$ separately from the 'economically active' is unfortunately not sufficiently reliable. However, it has already been shown that the quantity of HF consumed outside home per person (about $7 \mathrm{~g}$ ) is small compared with consumption at home (United Kingdom average $24 \cdot 2 \mathrm{~g}$ ). Furthermore, the first figure will not vary greatly from region to region, and it follows therefore that to a close approximation, relative SSMR values will depend simply upon relative values of $\mathbf{x}$. In other words, the rank order for decreasing SSMRs will be expected to reflect that of decreasing home HF consumption (and hence also of SMR magnitudes). In fact, Spearman rank order correlation between columns 7 and 15 gives $R(s)=0.85$ (excluding Wales, $R(s)=0.98)$.

In relation to its low home HF consumption, the Welsh region is again exceptional in having far too high a SSMR ('rural' Wales on the other hand has easily the lowest SSMR, as expected). This again would seem to point to some special factor operating, particularly in South-East Wales, which could possibly be the use of cheaper oils/fats for frying purposes.

Correlation of Social-Class Mortaltity and HF Consumption: Period 1959 to 1963

The NFSC data show that there is a class gradient in HF consumption increasing in the order $\mathrm{Al} \rightarrow$ $\mathrm{A} 2 \rightarrow \mathrm{B} \rightarrow(\mathrm{C}+\mathrm{D} 1)$. Thus for the major fat-containing 
food items listed in the Survey, during the six-year period 1958 to 1963, household HF consumptions were $19 \cdot 1,20 \cdot 6,22 \cdot 3$, and $24 \cdot 0 \mathrm{~g}$ respectively. These figures are based on the assumption that the fraction of lard in 'lard and compound cooking fat' is the same for all classes, that is, the national average of $70 \%$ as previously used in the regional analysis. The NFSC figures do not include minor food items such as crisps and ice-cream, or chips bought for home consumption. The figure for 'all households' is $22 \cdot 7 \mathrm{~g}$.

Table IV shows age-specific mortality ratios, all classes, England and Wales $=100$, in respect of the Registrar General's 'Group A' diseases, namely, 'cardiovascular diseases' (ICD, 7th Revisionwhich category consists essentially of vascular lesions of the central nervous system plus coronary disease; the nearest equivalent in the 8th Revision being cerebrovascular disease plus ischaemic heart disease) for men according to social class and married women according to their husbands' occupations.

TABLE IV

MORTALITY STATISTICS: CARDIOVASCULAR DISEASE: SOCIAL CLASSES

\begin{tabular}{|c|c|c|c|c|c|c|c|c|}
\hline \multirow{3}{*}{$\begin{array}{l}\text { Social } \\
\text { Class }\end{array}$} & \multicolumn{4}{|c|}{1959 to 1963} & \multicolumn{4}{|c|}{1949 to 1953} \\
\hline & \multicolumn{8}{|c|}{$\stackrel{\text { Men }}{\text { Mortality Ratios at Ages }}$} \\
\hline & $25-44$ & $45-54$ & $55-64$ & $65-69$ & $25-44$ & $45-54$ & $55-64$ & $65-69$ \\
\hline \multirow[t]{2}{*}{$\begin{array}{c}1 \\
2 \\
3 \\
4+5\end{array}$} & $\begin{array}{r}65 \\
84 \\
99 \\
117\end{array}$ & $\begin{array}{r}90 \\
86 \\
102 \\
107\end{array}$ & $\begin{array}{r}94 \\
93 \\
102 \\
102\end{array}$ & $\begin{array}{r}93 \\
94 \\
106 \\
97\end{array}$ & $\begin{array}{r}85 \\
99 \\
97 \\
110\end{array}$ & $\begin{array}{r}123 \\
104 \\
100 \\
95\end{array}$ & $\begin{array}{r}126 \\
102 \\
104 \\
91\end{array}$ & $\begin{array}{r}119 \\
100 \\
104 \\
93\end{array}$ \\
\hline & \multicolumn{8}{|c|}{ Married Women } \\
\hline $\begin{array}{c}1 \\
2 \\
3 \\
4+5\end{array}$ & $\begin{array}{r}58 \\
70 \\
100 \\
128\end{array}$ & $\begin{array}{r}57 \\
72 \\
101 \\
122\end{array}$ & $\begin{array}{r}65 \\
78 \\
100 \\
116\end{array}$ & $\begin{array}{r}64 \\
86 \\
102 \\
108\end{array}$ & $\begin{array}{r}63 \\
74 \\
99 \\
125\end{array}$ & $\begin{array}{r}82 \\
82 \\
101 \\
112\end{array}$ & $\begin{array}{r}93 \\
90 \\
101 \\
105\end{array}$ & $\begin{array}{r}96 \\
94 \\
102 \\
101\end{array}$ \\
\hline
\end{tabular}

The statistics cover the two five-year periods 1949 to 1953 and 1959 to 1963 . Subject to the assumption equating the Registrar General's social classes with NFSC income divisions (page 83), the increasing HF consumption is paralleled by increasing mortality at all ages for married women for the period 1959 to 1963. There is a similar correlation for men for the three age-groups up to 64 .

Unlike the small regional differences in total fat consumption, class differences are significant. Thus for $\mathrm{A1}$, the figure is $8 \mathrm{~g}$ higher than average, falling smoothly through A2 and B to $4 \mathrm{~g}$ lower than average for $(C+D 1)$. There is also a gradient in butter consumption, being highest for $\mathrm{A} 1$ ( $26 \mathrm{~g}$, fat content) and lowest for (C+D1) at a figure $18 \mathrm{~g}$. The situation for the earlier, 1949 to 1953 period will be considered later.

Secular Changes in Social-Class Mortality As pointed out by the Registrar General (1971), the social gradients in respect of Group A disease were largely reversed in the period from 1949 to 1953 and $\frac{\bar{\sigma}}{\bar{c}}$ 1959 to 1963 , whereas no such change occurred in, $\frac{\bar{\Phi}}{\Phi}$ for example, malignant neoplasm of the lung or $\stackrel{\mathbb{Q}}{\circ}$ hypertension. The change can readily be seen from the data in Table IV: thus, for example, compare the positive social-class gradient (in favour of class 1 ) for men over the 1959 to 1963 period for the age $\vec{\omega}$ groups 45 to 69 with the strong negative gradient?

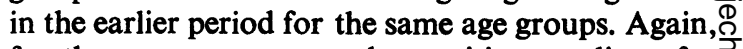
for the same age-span, the positive gradient for married women has intensified quite markedly. An alarming pattern which again emerges is the $e_{\infty}^{N}$ increasing risk at an earlier age-particularly in the ${ }^{N}$ 'lower' social classes.

The extent of the changes in mortality over the ${ }_{c}^{-}$ 10-year period is apparent from Table V: the figures are percentage decreases in death rates. In view of $\bar{乛}$ the fact that married women consume on average $\overrightarrow{0}$ fewer meals away from home (and thereby less Hig ,vे greater decreases in mortality for married women can therefore be expected, and occurring at all ages. The extent of improvement diminishes progressively from class 1 to class $(4+5)$ in agreement with the relativen falls in household HF consumption from a virtually common level over the war years to those previously quoted for about 1960.

Decreases occurred in men only for classes 1 and $2 ;$ for the other classes, mortality increased, particularly at an early age. These absolute decreases were due almost entirely to a drop in the death rate from ICD 330-334. This is claimed to be because of improve? ments in the medical treatment of hypertension. It is disturbing, therefore, to see that, in spite of the 'Welfare State', improvement has been very much in favour of the 'upper' classes; death rates for men of social classes 3,4 , and 5 have increased in the period?

The only absolute decrease due to ICD 420 is found in class 1 . Thus for the four age groups 45 to 54 . 55 to 64,65 to 69 , and 69 to 74 , the percentages reductions for men are $6,6,3$, and 3 respectively For married women, the reductions are (as expected higher i.e., 8, 16, 31, and 10 respectively. All othef classes showed increases but once again (as in com? bined cause group A) in the expected order.

\section{Married Women Versus Single Women MORTAlity PATtern}

It is well known that the overall mortality single women is greater than that of married women 
TABLE V

PERCENTAGE DECREASES IN MORTALITY RATES FROM CAUSE GROUP A; SOCIAL CLASSES; PERIOD 1949 TO 1953 TO PERIOD 1959 TO 1963

\begin{tabular}{c|c|r|r|r|r|r|r|r}
\hline \multirow{2}{*}{$\begin{array}{c}\text { Social } \\
\text { Class }\end{array}$} & \multicolumn{4}{|c|}{ Married Women } & \multicolumn{4}{c}{ Men } \\
\cline { 2 - 8 } & $25-44$ & $45-54$ & $55-64$ & $65-69$ & $25-44$ & $45-54$ & $55-64$ & $65-69$ \\
\hline 1 & 28 & 45 & 41 & 43 & 9 & 18 & 21 & 21 \\
2 & 25 & 30 & 28 & 22 & -3 & 7 & 4 & 5 \\
3 & 20 & 21 & 17 & 15 & -24 & -14 & -3 & -3 \\
$4+5$ & 19 & 14 & 7 & 8 & -28 & -27 & -16 & -6 \\
\hline
\end{tabular}

at ages 25 to 64 . In the opinion of the Registrar General (op. cit., p.29), this can partly be explained by selection of healthy women for marriage. However, it is clearly difficult to envisage such selection operating in early adult life in respect of mortality from cardiovascular disease.

Table VI compares death rates from ICD 420 by social class and age group for the period 1959 to 1963. The figures are ratios of death rates for single women to those for married women.

In as much as the married woman by definition is a woman whose husband is still alive, it could be argued that married women are in a favoured group, and therefore that the 'all-classes' higher mortality in single women is to be expected. It is difficult, however, on this basis alone to explain the marked class gradient in favour of the married woman of 'higher' social class. This peculiarity is, however, consistent with the reasonable expectation that in the 'lower' classes there would be a closer approach in eating-out habits and hence in HF consumption. Unfortunately no precise statistics regarding meals consumed in restaurants and canteens, etc., by the different social classes appear to be available. The quality of fat consumed outside home could again be an important factor.

\section{Overall Correlation: Social-Classes AND STANDARD REgIONS:}

Cardiovascular Disease: Period 1959 to 1963

The social-class mortality gradient exists within each standard region separately, so that the overall pattern which emerges is that arising from superimposing the class gradient upon the regional gradient. A reasonably smooth progression of increasing mortality is then found from class 1 in 'good' areas through intermediate classes in intermediate regions to class 5 in 'bad' areas. An example of the very wide mortality differences which thus arise is instructive: thus for class 1 (married woman) in areas such as the South-East and East Midlands, the SMR (15 to 64 ) is about 56 , whereas for class 5
TABLE VI

RATIO OF DEATH RATES, SINGLE: MARRIED WOMEN ICD 7TH REVISION, 420; SOCIAL CLASSES: 1959 TO 1963

\begin{tabular}{c|c|c|c}
\hline Classes & $25-54$ & $55-64$ & $65-69$ \\
\hline $1+2$ & 1.40 & 1.28 & 1.47 \\
$3+4$ & 1.15 & 1.06 & 1.32 \\
5 & 1.16 & 0.86 & 0.99 \\
All & 1.15 & 1.06 & 1.30 \\
\hline
\end{tabular}

in the North and North West, mortalities are about three times higher, about 170 SMR. It would therefore be of interest to compare this pattern with the HF consumptions of each of the four social groupings within each of the seven standard regions (Wales excepted), thus making a total of 28 'points'.

This has been carried out for married women on the following premises:

Relative populations for the social classes 1, 2, 3, and $(4+5)$ are sensibly constant over the seven regions.

It is reasonable to suppose that the ratio [Consumption in the private household for a particular class] to [Consumption in another class] is sensibly constant for each region. If this were not at least approximately true, regional differences could not exist.

The calculated consumptions do not allow for fat consumed outside home. Uncertainty of figures on eating-out habits is of lesser importance for women than for men. (This is consistent with the fact that, for men, the differential in mortality is much lower than the factor of three-times, as given above for the married woman.)

Figures therefore vary from $22 \cdot 7 \mathrm{~g}$ per married woman, class 1 , South West, to $35 \cdot 4 \mathrm{~g}$ for class $(4+5)$ for the North West.

These assumptions are admittedly crude, but in view of the great differences in mortality that exist, some correlation may be expected. In fact, a rather close correlation emerges as shown in the Figure, in which household consumption of HF in groups of approximately four 'points' is set against SMR values (15 to 64) for cardiovascular disease for the period 1959 to 1963 . The mortality ratios are taken from the Registrar General's Decennial Supplement, 1961.

The level of mortalities for the 1959 to 1963 period are therefore seen to be correlated solely with HF consumptions irrespective of geographical and social differences. This would imply that elimination 


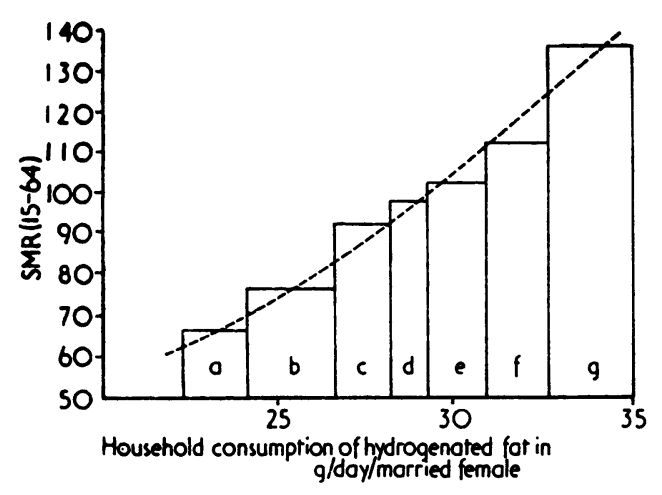

FIGURE. Standardized mortality ratios and household hydrogenated fat consumption, social classes and standard regions, cause group A, for married women during 1959 to 1963.

(a) South West, Class 1; West Midlands, Class 1; South West, Class 2; South East, Class 1; West Midlands, Class 2.

(b) South West, Class 3; South East, Class 2; East Midland, Class 1; North, Class 1.

(c) West Midlands, Class 3; South West, Class 4 and 5; South East, Class 3; Yorkshire and Humberside, Class 1; East Midlands, Class 2.

(d) West Midlands, Classes 4 and 5; North, Class 2; North West, Class 1.

(e) South East, Classes 4 and 5; Yorkshire and Humberside, Class 2; East Midlands, Class 3; North, Class 3.

(f) North West, Class 2; Yorkshire and Humberside, Class 3; East Midlands, Classes 4 and 5; North, Classes 4 and 5.

(g) North West, Class 3 ; Yorkshire and Humberside, Classes 4 and 5; North West, Classes 4 and 5.

of suspect fat from the diet would result in a fall in mortality to something like a common level in the community at large (see Table IV).

It could be argued that this correlation is purely an artefact arising from superimposing social class differences upon geographical differences as such, the class and regional HF gradients being purely coincidental. However, only 10 years previously, for the 1949 to 1953 period, the class mortality gradient was quite different.

\section{CONCLUSIONS}

It is felt that differing hydrogenated-fat consumptions account reasonably well for the main trends in regional and social class mortalities in respect of arteriosclerotic disease in the United Kingdom. In my opinion, a prima facie case against $\frac{}{\Phi}$

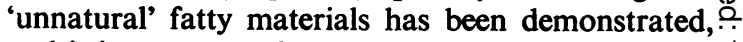
and it is a matter of some urgency that appropriate $\overrightarrow{\vec{F}}$ experimental work be conducted on the possible harmful effects of chemically altered glycerides of fatty acids up to $\mathrm{C}_{18}$ and of monoenoic or saturated $\mathrm{C}_{20}$ and $\mathrm{C}_{22}$ fatty-acid glycerides.

If a causal relationship exists, the secular changes $\varrho$ in regional and social-class mortalities that have $s$ occurred over the last two decades would suggest $\overrightarrow{0}$ that a rapid and substantial fall in mortality could be expected by appropriate adjustment of fat- $\vec{\omega}$ containing diet.

I wish to thank Professor R. F. Mahler of the Depart-i ment of Medicine, and Professor H. Campbell of the Department of Medical Statistics, University Hospital ${ }_{\infty}^{N}$ of Wales, Cardiff, for their encouragement and assistance. $N$ To Professor Campbell I am indebted for helpful criticism은 and suggestions in the preparation of the paper.

Requests for reprints: L. H. Thomas, MSc, FRIC,

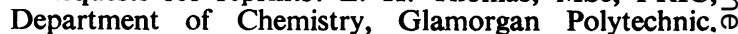
Llantwit Road, Treforest, Pontypridd.

\section{REFERENCES}

BRECH, R. J. (1959). Fatty foods and the pattern of their consumption in the United Kingdom. In: Proceedings of a Conference on the Chemistry and Technology of Edible Oils and Fats (Unilever Ltd.) edited by J. $\stackrel{\unrhd}{\varrho}$ Devine and P. N. Williams, p. 34 and Table 7. Per- $\overrightarrow{\vec{A}}$ gamon Press, Oxford.

DePartment of Trade AND Industry (1972). Catering Trades 1969: Statistical Inquiry. HMSO, London.

Kendall, M. G. (1970). Rank Correlation Methods, 4th ed. Griffin, London.

Ministry of Agriculture, Fisheries and FoOd (1956-72). Household Food Consumption and Expendi-3. ture, Annual Reports of the National Food Survey Committee 1955-1971. HMSO, London.

Registrar General (1971). Decennial Supplement, 옹 England and Wales 1961, Occupational Mortality Tables, p. 35. HMSO, London. 